\title{
Zafirlukast in combination with pseudohypericin attenuates spinal cord injury and motor function in experimental mice
}

This article was published in the following Dove Press journal: Drug Design, Development and Therapy

\author{
Xiao-Gang Chen' \\ $\mathrm{Fu} \mathrm{Hua}{ }^{2}$ \\ Shou-Guo Wang' \\ Yong-Yi Xu' \\ Hai-Tao Yue \\ Jin Sun'
}

'Department of Orthopedics, Huai'an First People's Hospital, Nanjing Medical University, Huai'an, Jiangsu 223300, People's Republic of China; 2Department of Gynaecology, Huai'an First People's Hospital, Nanjing Medical University, Huai'an, Jiangsu 223300, People's Republic of China

Correspondence: Xiao-Gang Chen Department of Orthopedics, Huai'an First People's Hospital, Nanjing Medical University, No 6, Beijing West Road, Huai'an, Jiangsu 223300, People's

Republic of China

Email xopfix49305I@163.com
Background: Biosynthesis of leukotriene (LT) by arachidonic acid involves 5-lipoxygenase (5-LO) as an important precursor. Here, we evaluated the role of pseudohypericin (PHP) for its postulated 5-LO inhibitory activity along with a Cys-LT receptor antagonist zafirlukast (ZFL) against inflammatory response and tissue injury in mice.

Materials and methods: The spinal injury was induced by two-level laminectomy of T6 and T7 vertebrae. The inflammation was assessed by histology, inflammatory mediators by enzymelinked immunosorbent assay, apoptosis by Annexin-V, FAS staining, terminal deoxynucleotidyltransferase-mediated UTP end labeling (TUNEL) assay and expression of Bax and Bcl-2 by Western blot. Effect on motor recovery of hind limbs was evaluated for 10 days postinjury.

Results: The spinal injury resulted in tissue damage, apoptosis, edema, infiltration of neutrophils with increased expression of tumor necrosis factor- $\alpha$ (TNF- $\alpha$ ) and cyclooxygenase-2 (COX-2). The spinal tissue showed elevated levels of prostaglandin $\mathrm{E}_{2}$ (PGE2), and $\mathrm{LTB}_{4}$ and increased phosphorylation of injured extracellular signal-regulated kinase-1/2 (ERK1/2). The PHP, ZFL and combination decreased inflammation, tissue injury and infiltration of neutrophils. Treatment also decreased the levels of $\mathrm{PGE}_{2}$, phosphorylation of extracellular signal-regulated kinase- $1 / 2$ (pERK 1/2), LT, TNF- $\alpha$ and COX-2 with a marked reduction in apoptosis and improved the motor function.

Conclusion: The present study confirmed 5-LO antagonist activity of PHP and established its neuroprotective role along with ZFL.

Keywords: pseudohypericin, zafirlukast, 5-lipoxygenase, Cys-LT, mice

\section{Introduction}

Spinal cord injury (SCI) is an unanticipated event, which largely affects not only the patient but also the other members of the family. SCI initiates a large number of cellular events associated with a further progressive neuronal injury along with secondary factors such as ischemia, apoptosis, ${ }^{1,2}$ alterations in biochemical parameters, accumulation of neurotransmitters, free radical-mediated lipid peroxidation and excitotoxicity. ${ }^{3}$ Inflammation and immune response play a crucial role in the pathogenesis of SCI. ${ }^{4}$ SCI is associated with a series of events causing degeneration of neurons, such as activation of mitogen-activated protein kinase (MAPK), the release of inflammatory mediators, particularly tumor necrosis factor- $\alpha$ (TNF- $\alpha$ ), nitric oxide (NO), prostaglandins (PGs) and leukotrienes (LTs). Among all these events phosphorylation of extracellular signal-regulated kinase-1/2 (pERK-1/2), ie, ERK-1/2, causes activation of genes responsible for initiating inflammatory responses. The gene evokes encryption for TNF- $\alpha$ and the cyclooxygenase- 2 (COX-2). Inflammation-mediated damage of 
endothelial cells may be the etiology behind the secondary injury process. ${ }^{6}$ SCI is majorly caused by infiltration of neutrophils in the injured part ${ }^{7,8}$ and leads to endothelial cell injury by releasing inflammatory mediators such as NO, cytokines, 5-lipoxygenase (5-LO) metabolites, interleukins (IL) and COX-2. ${ }^{9-14}$ Infiltration of neutrophils is proportional to the extent of trauma and the leukotriene $\mathrm{B}_{4}\left(\mathrm{LTB}_{4}\right)$ quantity (5-LO product $)^{9,12}$ and a report also suggest higher generation rate of leukotriene $\mathrm{C} 4$ (LTC4) in SCI. ${ }^{15}$

Hypericum perforatum $\mathrm{L}$ is a plant of the genus Hypericum (Clusiaceae), the plants of which are widely distributed all over the world and have been used from historic times for a range of medicinal properties. ${ }^{16}$ The plant extract has shown promising role as an anti-inflammatory agent in chronic as well as in acute diseases ${ }^{17}$ due to the modulating action on the expression of COX-2, an important mediator of inflammation. The plant extract has been reported to inhibit the synthesis of TNF- $\alpha$, which is a proinflammatory cytokine, and interleukin-10 (IL-10), which is an anti-inflammatory cytokine. ${ }^{18}$ Pseudohypericin (PHP) is an active compound of the plant $H$. perforatum (St John's wort) and structurally belongs to the chemical class of naphthodianthrones. The class of compounds has been confirmed for antilipoxygenase activity. ${ }^{19}$

Cysteinyl leukotriene-1 (CysLTR1) antagonists such as montelukast have been reported for protective effect against ischemia-mediated injury in tissues such as in the heart, liver, kidneys and spinal cord via reducing inflammation and oxidative stress. ${ }^{20}$

In the present study, we particularly evaluated the role of a naphthodianthrones class of compound, ie, PHP in combination with a CysLTR1 antagonist agent, ie, zafirlukast (ZFL) in a SCI mice model.

\section{Materials and methods Drugs and chemical reagents}

PHP and ZFL were procured from Sigma-Aldrich Co., St Louis, MO, USA. Avidin and biotin were procured from Merck \& Co., Inc. The antibodies against Bcl-2, Bax, ERK-2 and pERK-1/2 were bought from Calbiochem Corp. (San Diego, CA, USA). The antibody against COX-2 was procured from Abcam (Cambridge, USA). All the other required reagents and chemicals were of analytical reagent grade and were procured from Sigma-Aldrich.

\section{Induction of $\mathrm{SCl}$ in mice}

All the experimental protocols over animals were in accordance with the animal ethical committee, Department of
Orthopedics, Huai'an First People's Hospital, Nanjing Medical University, China. The approval number was NMU/ DO/AEC/2016/E45. For the study, a total of 36 male CD1 mice, weighing $\sim 30 \mathrm{~g}$, were selected and were kept in polypropylene cages under controlled conditions of environment. They were given recommended diet consisting rodent chow along with water. SCI was induced by extradural compression of the spinal cord; briefly, the mice were subjected to phenobarbital $1 \%$ anesthesia. In the midline of the back, a longitudinal incision was made for exposing paravertebral muscles followed by dissecting them and exposing vertebrae T5-T8. A two-level laminectomy of T6-T7 was opted for to expose vertebrae. The aneurysm clip selected had a closing force of $24 \mathrm{~g}$ and was utilized for creating spinal compression for $1 \mathrm{~min}$ inducing SCI. The sham-operated group mice were subjected to laminectomy only. All the operated mice were injected with saline solution subcutaneously to recover blood volume loss during surgery. During the recovery period from anesthesia, all the animals were placed on a warm heating pad followed by cover with a warm towel. After surgery, all the animals were housed individually under controlled conditions of temperature $\left(27^{\circ} \mathrm{C}\right)$ for 10 days with recommended food and water. During the recovery period of 10 days, the bladders of operated mice were emptied manually two times in a day until the animals were able to gain normal bladder function.

\section{Treatment protocol}

The SCI-induced mice were selected randomly and were divided into 1$)$ the vehicle-treated control group, saline $(0.9 \%$ sodium chloride) was the vehicle given intraperitoneally twice a day $(\mathrm{n}=50)$; 2) PHP-treated group, PHP was given (120 $\mu \mathrm{g} \mathrm{kg}^{-1}$ of body weight) orally twice a day ${ }^{21}(\mathrm{n}=50)$; 3) ZFL-treated group, ZFL (10 $\mathrm{mg} \mathrm{kg}^{-1}$ body weight) was administered in saline po, twice in a day $(n=50)$; 4) PHPZFL-treated group, the mice were treated with the combination of PHP $\left(120 \mu \mathrm{g} \mathrm{kg}^{-1}\right)+\mathrm{ZFL}\left(10 \mathrm{mg} \mathrm{kg}^{-1}\right)$ of body weight two times in a day by per os (po) route $(n=50)$; 5) Shamoperated vehicle-treated group (dissected for T6-T7 laminectomy) treated with vehicle, ie, saline by po route $(n=50)$.

\section{Histological studies}

The spinal cord histological studies were done by collecting spinal cord biopsies $24 \mathrm{~h}$ after inducing SCI. The tissue sections were $5-\mu \mathrm{m}$ thick and were cut longitudinally, prior to this the spinal tissue segments bearing lesions were embedded in paraffin. The obtained tissue sections were subjected to deparaffinization using xylene followed by staining with hematoxylin/eosin and light microscopy studies. 


\section{Evaluation of motor function in mice}

Effect of SCI on motor function was assessed in mice subjected to spinal injury once in a day for 10 days after subjecting them to injury. The disturbances in motor function were graded as per the model suggested by Basso et al and Joshi and Fehlings. ${ }^{22,23}$ For evaluation of motor function, certain criteria were decided as per the refereed studies as described. 1) Absence of hindlimb movement. 2) Slight motion $(>50 \%)$ of one to two joints. 3) Extensive movements of both the joints of limb. 4) Slight movement in all three joints. 5) Slight movement of two joints and extensive movement of the third joint. 6) Extensive movement of two joints and diminished movement of the third. 7) Enhanced movement in all three joints. 8) No coordination between front/hindlimb. 9) Sweeping of front and hindlimbs without support. 10) Placement of plantar with weight support in stance only. 11) No coordination and consistent plantar steps supported with weight. 12) Frequent occurrence of plantar steps with weight support. 13) Continuous and coordinated plantar steps supported by weight. 14) Plantar steps with coordination, without toe clearance and with parallel paw position. 15) Continuous and coordinated plantar steps with predominant paw position. 16) Continuous plantar stepping with coordination and frequent clearance of toe.

\section{Evaluation of myeloperoxidase (MPO) activity}

Polymorphonuclear leukocyte accumulation was determined by evaluation of MPO activity done $24 \mathrm{~h}$ after induction of SCI, as described by Mullane et al. ${ }^{24}$ Spinal cord tissues of mice were removed, weighed and subjected to homogenization in a solution of hexadecyl trimethyl ammonium bromide $(0.5 \%$ weight/volume $[\mathrm{w} / \mathrm{v}])$ prepared in phosphate buffer $(10 \mathrm{mM}, \mathrm{pH} 7)$ and finally centrifuged at $20,000 \times \mathrm{g}$ in a cooling centrifuge at $4^{\circ} \mathrm{C}$ for $30 \mathrm{~min}$. The obtained supernatant was reacted with $1.6 \mathrm{mM}$ tetra-methylbenzidine and $0.1 \mathrm{mM}$ $\mathrm{H}_{2} \mathrm{O}_{2}$. The resultant was analyzed by UV-Spectrophotometer (Shimadzu-1800) at $650 \mathrm{~nm}$ to mark the changes in absorbance with time. The activity of MPO was described as the fraction of enzyme degrading $1 \mu \mathrm{mol}$ of peroxide $\mathrm{min}^{-1}$ at room temperature (ie, $37^{\circ} \mathrm{C}$ ) values expressed as $\mu \mathrm{g}^{-1}$ of tissue.

\section{Immunohistochemistry studies}

Immunohistochemical studies were done for localization of Bax, Bcl-2, TNF- $\alpha$, FAS ligand and MPO in SCI tissues of spinal injured mice. The spinal tissues were fixed after $24 \mathrm{~h}$ post-SCI in phosphate-buffered saline (PBS, $10 \% \mathrm{w} / \mathrm{v}$ ) and formaldehyde, the tissues were fixed in paraffin and sections of $8 \mu \mathrm{m}$ were prepared. The sections were deparaffinized and endogenous peroxidase was quenched using $\mathrm{H}_{2} \mathrm{O}_{2}(0.3 \% \mathrm{v} / \mathrm{v})$ in methanol $(60 \% \mathrm{v} / \mathrm{v})$ for $30 \mathrm{~min}$. Triton $\mathrm{X}-100$ solution in PBS $(0.1 \% \mathrm{w} / \mathrm{v})$ was used to increase the permeability of sections. Prior to staining the sections were incubated with $2 \%$ solution of normal goat serum prepared in PBS (20 min) for minimizing nonspecific adsorption. The sections were then incubated sequentially with biotin and avidin (15 min) for blocking the binding sites. The sections were then subjected to incubation overnight with anti-MPO, anti-FAS ligand or anti-Bax rabbit polyclonal antibody, the anti-Bcl-2 and anti-TNF- $\alpha$ polyclonal rat antibody (1:500 in PBS). Densitometry studies were carried to evaluate immunohistochemical photographs ( $\mathrm{n}=3$ photos/sample from each experimental group). In the process to evaluate the levels of TNF- $\alpha$ in tissues, the tissues were homogenized similarly as done before in $2 \mathrm{mM}$ phenylmethyl sulphonyl fluoride solution in PBS. The assay of TNF- $\alpha$ was based on a colorimetric procedure as per the manufacturer instructions (Abcam), the determinations were in triplicate for each serial dilution.

\section{Annexin- $\mathrm{V}$ and propidium iodide $(\mathrm{PI})$ staining studies}

Measurement of apoptosis in spinal cord tissue sections was done by Annexin-V-PI kit (Abcam) as per the provided instructions. Briefly, the normal cells on exposure show negative staining for both Annexin-V FITC and PI, the cells subjected to apoptosis show positive staining for Annexin- $\mathrm{V}$ FITC and negative staining for PI, whereas the cells undergoing apoptosis and necrosis in later stages show positive staining for both Annexin-V FITC and PI. After staining, the sections were buffer washed, treated with $90 \%$ glycerin in PBS and mounted. The sections were observed with a (Carl-Zeiss-Straße, Germany) confocal microscope (LSM510) using an oil emersion objective at $40 \times$.

\section{Terminal deoxynucleotidyltransferase- mediated UTP end labeling (TUNEL) assay} A TUNEL detection kit (Abcam) was used for conducting end labeling assay. As per manufacturer's instructions, sections of tissues were incubated with $15 \mu \mathrm{g} \mathrm{mL}^{-1}$ of proteinase kinase for $15 \mathrm{~min}$ at room temperature followed by washing with PBS. A solution of $3 \% \mathrm{H}_{2} \mathrm{O}_{2}$ was used to inactivate endogenous peroxidase enzyme ( $5 \mathrm{~min}$ ) followed by washing using PBS. The tissue sections were then immersed in a mixture of deoxynucleotidyl transferase and biotinylated deoxyuridine triphosphate in terminal deoxynucleotidyl transferase (TdT) 
buffer, incubation was done under humid conditions at $37^{\circ} \mathrm{C}$ for $90 \mathrm{~min}$ and finally washed with PBS. The sections were subjected to incubation at room temperature of $37^{\circ} \mathrm{C}$ for 30 min with an anti-horseradish peroxidase-conjugated antibody; the signals were visualized using diaminobenzidine.

\section{Western blot analysis for apoptotic transcriptional changes}

The spinal cord tissues obtained from spinal-injured mice were subjected to homogenization in a solution containing $20 \mathrm{mM}$ hydroxyethyl piperazineethanesulfonic acid (HEPS) buffer of $\mathrm{pH} 7.6, \mathrm{NaCl}(400 \mathrm{mM}), \mathrm{MgCl}_{2}(1.5 \mathrm{mM})$, ethylene glycolbis( $\beta$-aminoethyl ether)-N,N,N', $\mathrm{N}^{\prime}$-tetraacetic acid (EGTA) $(1 \mathrm{mM})$, EDTA $(1 \mathrm{mM})$, trypsin inhibitor $\left(15 \mu \mathrm{g} \mathrm{ml}^{-1}\right)$, dithiothreitol $(1 \mathrm{mM})$, phenylmethylsulfonyl $(0.5 \mathrm{mM})$ fluoride, leupeptin $\left(2 \mu \mathrm{g} \mathrm{ml}^{-1}\right)$, benzamidine $(40 \mathrm{mM})$, pepstatin $\left(3 \mu \mathrm{g} \mathrm{ml}^{-1}\right)$, Nonidet P40 (1\%) (Sigma-Aldrich), glycerin (20\%) and NaF (50 mM). Homogenates were subjected to 15 min centrifugation at $10,000 \times g$ at $4^{\circ} \mathrm{C}$, proteins were determined in the supernatant using protein estimation kit (Abcam). Gel-loading buffer (Tris [50 mM], glycerol [10\%], 2-mercaptoethanol [10\%], sodium dodecyl sulfate [10\%] and $2 \mathrm{mg} \mathrm{ml}^{-1}$ of bromophenol) and protein $(50 \mathrm{mg})$ were mixed in equal amounts followed by boiling for $3 \mathrm{~min}$ and centrifuged for $10 \mathrm{~min}$ at $12,000 \times \mathrm{g}$. Electrophoresis was done on sodium dodecyl sulfatepolyacrylamide gel $(10 \%)$. The proteins after transferring on nitrocellulose membranes were blocked using PBS (0.1\%) and nonfat containing dry milk (5\%) for COX-2, ERK-2, Bcl-2 and $\beta$-actin, for $\mathrm{pERK}-1 / 2$, PBS-Tween $(0.1 \%)$ containing non-fat dry milk (5\%) and $\mathrm{NaF}(50 \mathrm{mM})$. The membranes were then incubated at $4^{\circ} \mathrm{C}$ with primary antibody overnight. Rabbit monoclonal antibodies i.e. anti-COX-2 (Santa Cruz Biotechnology), anti-Bcl-2, anti-Bax and the mouse monoclonal antibody i.e anti-ERK-2 were subjected to dilution in ratio 1:1000 in phosphate buffer saline and Tween-20, non-fat containing dry milk $(5 \%)$ and sodium fluoride $50 \mathrm{mM}$. Anti- $\beta$-actin the mouse monoclonal antibody (Sigma-Aldrich) was diluted in a ratio of $1: 1,000$ in the mixture of PBS-Tween-20 (0.1\%), BSA (5\%). Postincubation, the membranes were subjected to washing at least six times each using PBS-Tween $(0.1 \%)$ and subjected to incubation for $90 \mathrm{~min}$ at room temperature with horseradish peroxidase-conjugated anti-mouse secondary antibodies in ratio 1:1,000. The membranes after washing were visualized for bands employing chemiluminescence system (Thermo Fisher Scientific, Waltham, MA, USA) and densitometry studies by an imaging system (Thermo Fisher Scientific). The densitometry analyses of Western blots were normalized by loading control and expressed as fold changes with respect to controls.
Estimation of prostaglandin E2 $\left(\mathrm{PGE}_{2}\right)$ and $\mathrm{LTB}_{4}$ levels in injured spinal cord tissues

The spinal tissues were collected $24 \mathrm{~h}$ after injury and were homogenized in methanol. The $\mathrm{PGE}_{2}$ and $\mathrm{LTB}_{4}$ were recovered in methanol $(5 \mathrm{~mL})$ at $-80^{\circ} \mathrm{C}$, for next $3-5$ days. The obtained extracts were subjected to 15 min centrifugation at $12,000 \times g$ to remove tissue debris. Excess of methanol was dried and the samples were analyzed using enzyme-linked immunosorbent assay ELISA kit (Abcam) by suspending them in provided buffer. To estimate the levels of $\mathrm{PGE}_{2}$ and $\mathrm{LTB}_{4}$, dilutions were done further 1-20-fold and analyzed using multiple dilutions.

\section{Statistical procedures}

All values expressed in the graphs are mean \pm SE of " $n$ " observations. For the animal studies, n represents the number of animals evaluated. In the histology or immunohistochemistry studies, the figures presented are representative of at least three independent experiments performed on different tissue sections and days from animals in each group $(n=10)$. The results were statistically tested by one-way ANOVA followed by a Bonferroni post hoc test for multiple comparisons; $P<0.05$ was considered significant. Basso, Beattie and Bresnahan (BBB) scale data were analyzed by the Mann-Whitney test and considered significant when $P<0.05$.

\section{Results \\ Effects of PHP and ZFL on the severity of $\mathrm{SCl}$}

After $24 \mathrm{~h}$, a significant extent of damage was observed in spinal tissues recovered from experimental mice of vehicletreated control group, marked by the occurrence of edema and changes in white matter of perilesional zone (Figure 1A) compared to sham group mice (Figure 1B). The severity of SCI decreased in tissues obtained from PHP-treated mice (Figure 1C) and SCI-ZFL (Figure 1D), whereas a significant reduction in edema was seen in spinal tissues of PHP-ZFLtreated mice (Figure 1E).

To establish a correlation between histological damage to the spinal cord and altered motor function, we used the hindlimb locomotor-rating scale by BBB (motor score). The sham-operated group of mice showed a slight impaired motor function (Figure 2), the vehicle-treated mice showed impaired locomotor activity and had a major defect in movements of hindlimb (Figure 2), whereas improved $(P<0.01)$ motor function was observed in PHP, ZFL and their combination, ie, PHP-ZFL-treated mice (Figure 2). The BBB motor score values improved significantly from fifth day $(P<0.05)$ 

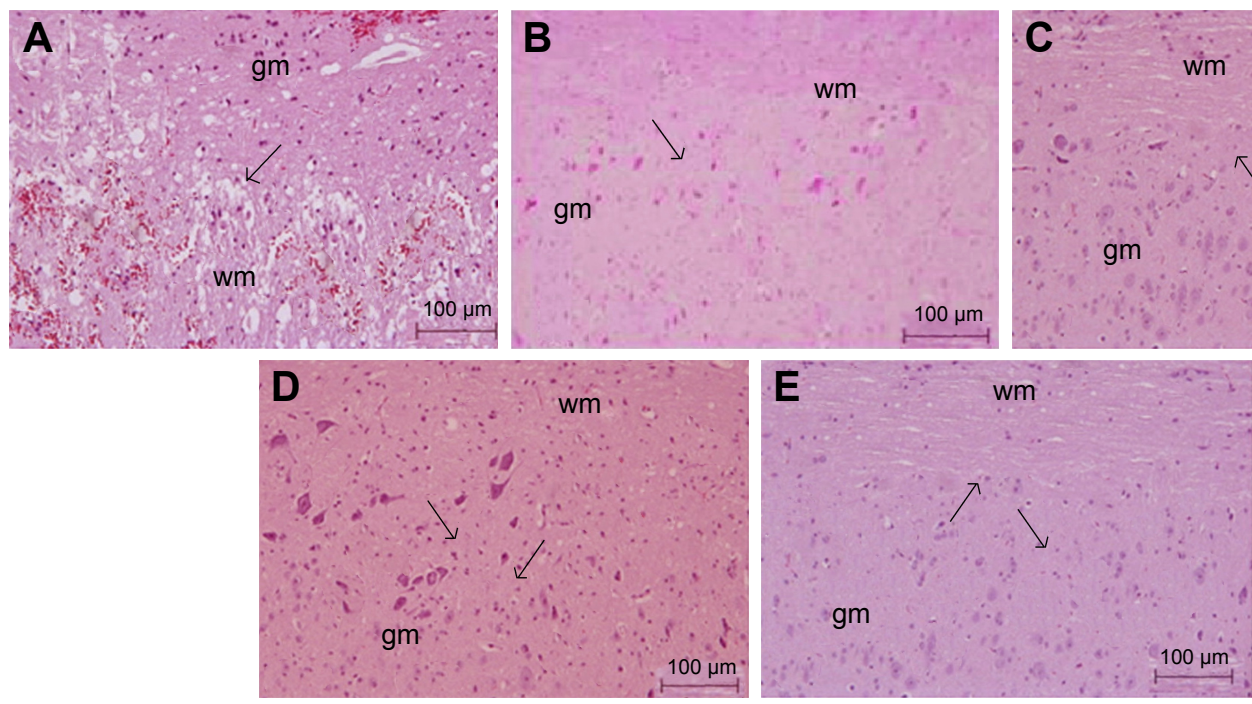

Figure I Effect of pseudohypericin and zafirlukast on histological changes on the spinal cord tissue $24 \mathrm{~h}$ after inducing spinal injury.

Notes: (A) Vehicle-treated control group showing occurrence of edema and changes in white matter of perilesional zone. (B) Sham-vehicle-treated group mice showing no signs of changes. The severity of spinal cord injury decreased in tissues with reduction in edema and preservation of white matter observed in sections (C) pseudohypericinand (D) zafirlukast-treated mice. The results were improved in (E) after combining pseudohypericin and zafirlukast. The produced figures are representatives of three experiments. The arrows show the changes in white matter suggesting spinal tissue injury.

Abbreviations: wm, white matter; gm, gray matter.

in PHP-ZFL-treated mice compared to their individual treatment (Figure 2).

\section{Effects of PHP and ZFL on infiltration of neutrophils}

The vehicle-treated control group mice showed elevated MPO activity $(P<0.001) 24 \mathrm{~h}$ after injury as against sham

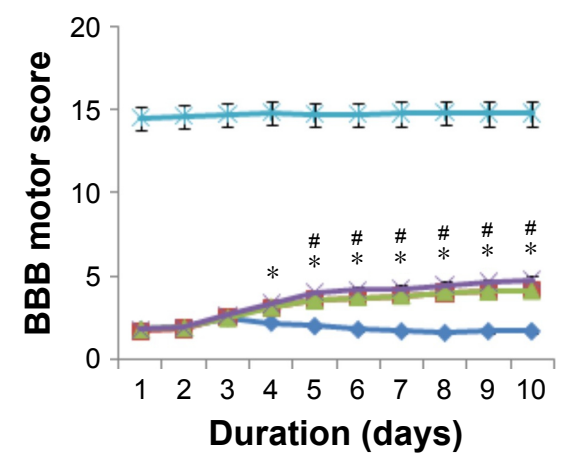

\begin{tabular}{ll|}
$-\leftarrow$ Control & - PHP-treated \\
$\rightarrow$ PHP-ZFL-treated & - Sham-operated \\
- & \\
\hline
\end{tabular}

Figure 2 Effect of PHP and ZFL on motor dysfunction after spinal cord injury. Notes: The findings were the outcome of BBB motor score, ${ }^{22}$ the mice were evaluated for motor activity daily for 10 days after inducing spinal injury. Highly significant $(* P<0.001)$ improvement in motor score was seen in mice treated with PHP, ZFL and their combination compared to control-vehicle-treated group. The values of BBB motor score were significant in PHP-ZFL-treated mice compared to their individual treatment $\left({ }^{\#} P<0.05\right)$.

Abbreviations: PHP, pseudohypericin; ZFL, zafirlukast; BBB, Basso-BeattieBresnahan. operated-vehicle-treated mice (Figure 3). Significantly decreased MPO activity was observed in spinal tissues of PHP-treated and ZFL-treated mice $24 \mathrm{~h}$ after spinal injury. The levels of MPO after $24 \mathrm{~h}$ in PHP-ZFL-treated mice decreased even more significantly as compared to their individual treatments $(P<0.001)$.

On localization of MPO in tissue sections of spinal cords post $24 \mathrm{~h} \mathrm{SCI}$, the tissues of vehicle-treated control group mice stained positive for MPO, localized primarily in the injured area infiltrated with neutrophils (Figure 3A), The sham-operated mice do not show any signs of MPO localization in tissues (Figure 3B). However, in mice treated with PHP (Figure 3C) and ZFL (Figure 3D), a markable reduction in staining of MPO was seen as compared to vehicle-treated control group. The staining of MPO was reduced even more (not significantly) in tissues of mice treated with a combination of PHP-ZFL compared to their individual treatments (Figure 3E).

\section{Effects of PHP and ZFL on levels of TNF- $\alpha$ (immunohistological analysis)}

The study was done to mark the effect of PHP and ZFL and their combination on levels of TNF- $\alpha$, a cytokine responsible for the secondary inflammatory reaction. The TNF- $\alpha$ level in spinal tissues after subjecting the mice to injury was done by immunohistological analysis. Results of the study suggested significantly increased levels of TNF- $\alpha$ (Figures 4 and 5F) 

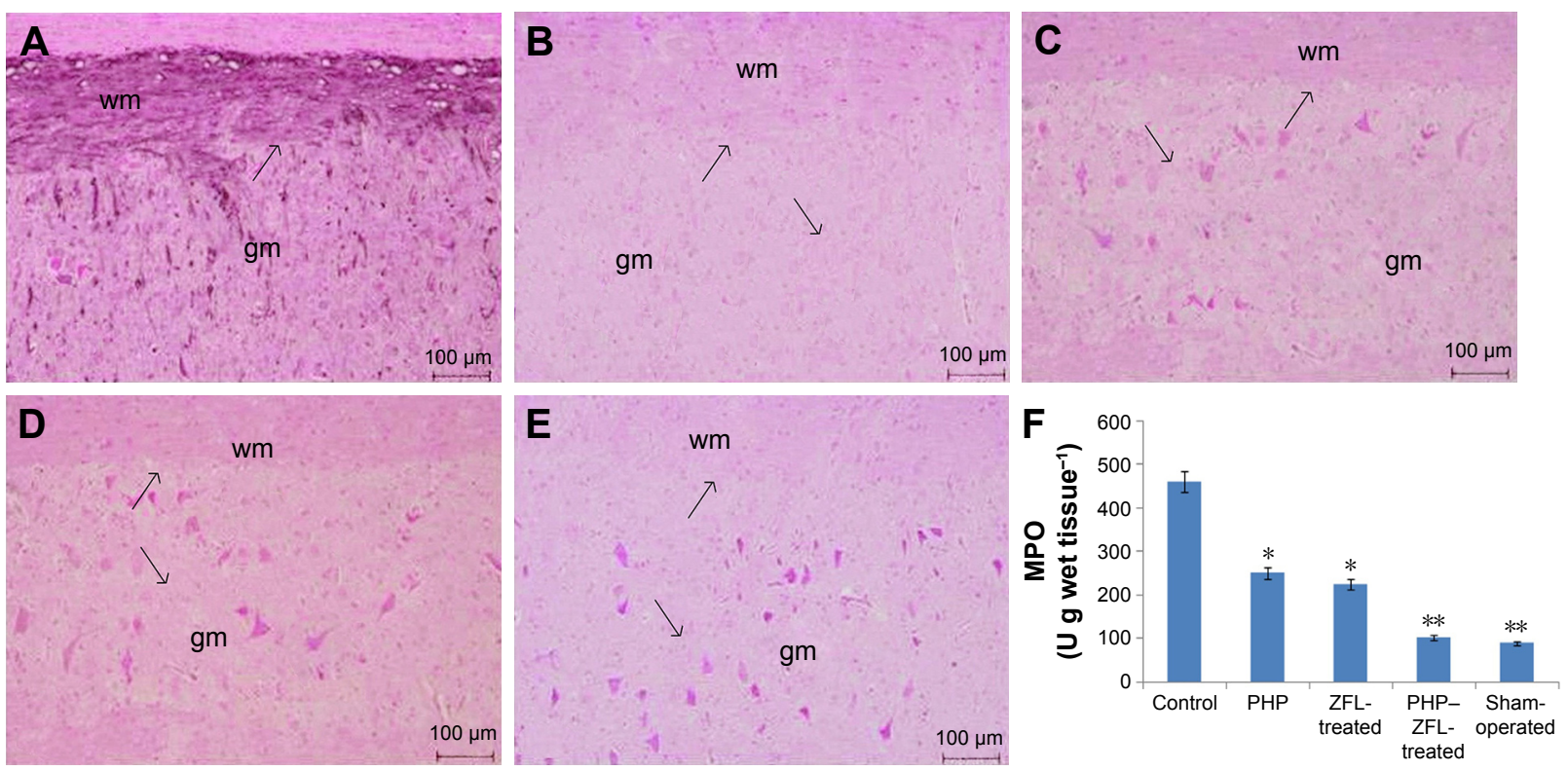

Figure 3 Immunohistochemical localization and activity of MPO in spinal tissue of mice treated with PHP and ZFL their combination.

Notes: In vehicle-treated control group mice, the tissue stained positive for MPO and presented increased MPO activity (A and F). Sham-operated group mice, tissue sections showed no positive staining for MPO and also had normalized MPO activity (B and F). MPO staining in tissues sections from PHP (C), ZFL (D) and their combination (E) a significant reduction in positive staining for MPO activity was seen compared to vehicle-treated control group. The produced figures are representatives of three experiments. Data are mean $\pm \% R S D(n=10), * P<0.01, * * P<0.001$ compared to control vehicle-treated mice. The arrows show the pink coloration that indicates the localization of MPO activity.

Abbreviations: MPO, myeloperoxidase; PHP, pseudohypericin; ZFL, zafirlukast; wm, white matter; gm, gray matter; RSD, relative standard deviation.

in vehicle-treated control group mice at $24 \mathrm{~h}$ post-SCI. Intake of both PHP and ZFL attenuated the elevated levels of TNF- $\alpha$ (Figures 4 and 5), the experimental outcomes got even improved when the mice were treated with the combination of PHP-ZFL. No staining of TNF- $\alpha$ was seen in sham-operated and vehicle-treated mice.

\section{Effects of PHP and ZFL on apoptosis (Annexin- $\mathrm{V}$ and $\mathrm{PI}$ )}

The extent of Annexin-V staining of spinal cord tissue cells was measured in order to evaluate injury-mediated apoptosis

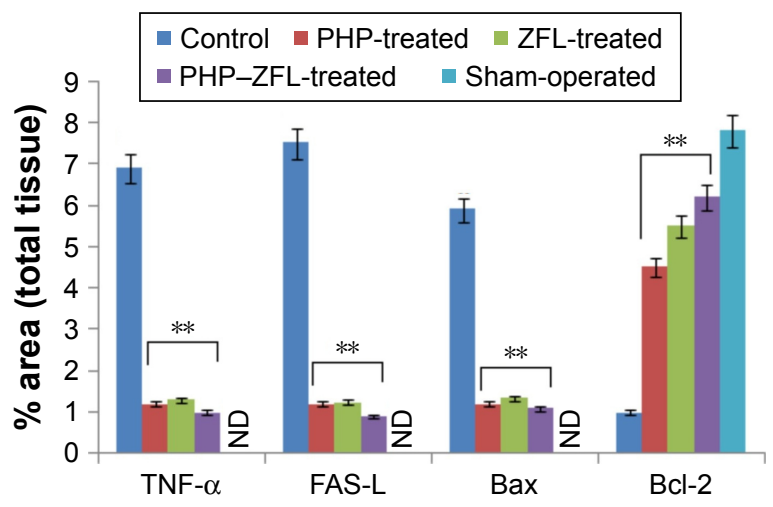

Figure 4 Densitometry studies of immunocytochemistry images of spinal tissue sections for levels of TNF- $\alpha$, Bax, FAS-L and Bcl-2.

Notes: All the data are presented as $\%$ of total tissue area. $* * P<0.001$ compared to control group.

Abbreviations: TNF- $\alpha$, tumor necrosis factor- $\alpha$; ND, not detectable; PHP, pseudohypericin; ZFL, zafirlukast; FAS-L, FAS ligand. of cells. No sign of apoptosis was seen in the spinal tissue of sham-operated mice (data not presented). However, in control group mice $24 \mathrm{~h}$ after SCI, the spinal tissues demonstrated marked appearance of Annexin- $\mathrm{V}$ positively stained cells (Figure 6A), indicating the cells undergoing apoptosis. The cells of the control group were positive for PI intracellular staining (cell index representing apoptosis of late-stage) (Figure 6A). Contrarily, the tissues of shamgroup mice (Figure 6B) and those receiving treatment of PHP, ZFL and their combination showed significant downfall in a number of Annexin-V and PI-positive cells compared to control group (Figure 6C-E, respectively). However, the decrease in Annexin- $\mathrm{V}$ and $\mathrm{PI}-$ positive cells was even more significant in PHP-ZFL-treated group compared to their individual treatment, suggesting a potentiating effect of the combination.

\section{Effects of PHP and ZFL on tissue damage- associated apoptosis (TUNEL assay and immunohistological staining for FAS ligand)}

The study was further proceeded to find whether the damage of spinal tissue was linked to cell death by apoptosis, the study was done by TUNEL staining assay. The outcomes of TUNEL assay suggested no apoptotic cell death in spinal tissues of sham-operated group mice. In contrast, the spinal tissues obtained after $24 \mathrm{~h}$ of injury in vehicle-treated control group mice showed a significant increase $(P<0.001)$ in 

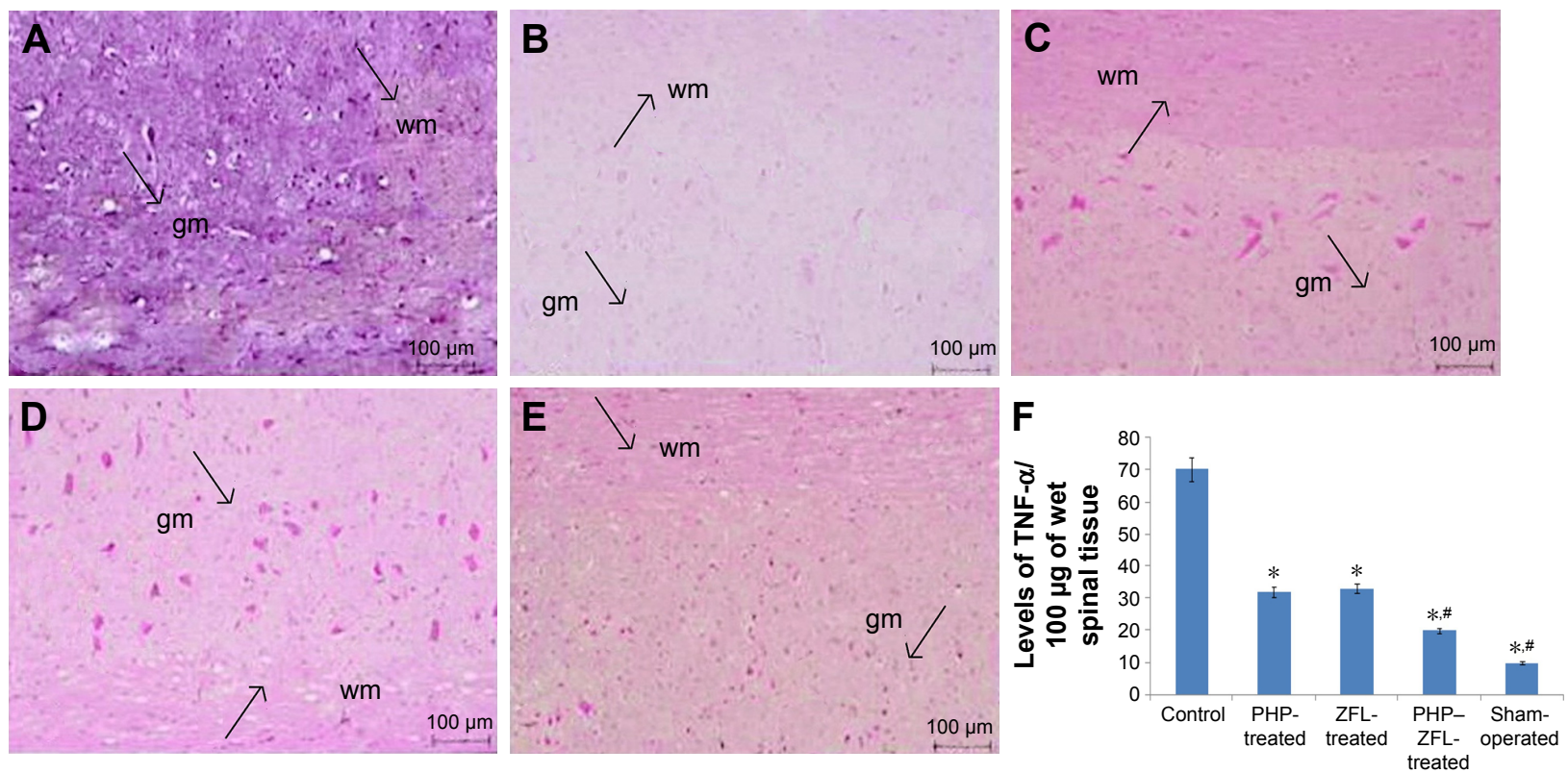

Figure 5 Effect of PHP and ZFL on tissue levels and immunohistochemical localization of TNF- $\alpha$.

Notes: The control vehicle-treated group showed increased levels of TNF- $\alpha$ and positive staining in spinal tissues (A). (B) Sham-group did not exhibit staining. The treatment of PHP, ZFL and their combination significantly $(* P<0.01)$ reduced levels of TNF- $\alpha$ compared to control $(\mathbf{F})$, also reduced the positive staining in spinal tissues $(\mathbf{C}$, $\mathbf{D}$ and E, respectively). The results were highly significant $\left({ }^{\sharp} P<0.001\right)$ in mice treated with combination of PHP and ZFL and sham group compared to control. The arrows indicate the localization of TNF staining in spinal tissues.

Abbreviations: PHP, pseudohypericin; ZFL, zafirlukast; TNF- $\alpha$, tumor necrosis factor- $\alpha$; wm, white matter; gm, gray matter.

number of apoptotic cells appearing dark-brown in color defined to be TUNEL-positive cells (Figure 7A), suggesting a significant role of spinal injury in apoptosis. The tissues sections of sham group showed very few or no TUNELpositive cells (Figure 7B). However, signs of attenuation were seen in PHP- (Figure 7C) or ZFL-treated mice (Figure 7D), the number of TUNEL-positive dark-brown cells decreased significantly compared to control group mice. Highly significant outcome was seen in mice treated with the combination of PHP and ZFL, the number of dark-brown color TUNEL-positive cells decreased significantly compared to control $(P<0.001)$ in PHP- and ZFL-treated group of mice $(P<0.01)$ (Figure $7 \mathrm{E})$.

After $24 \mathrm{~h}$ of spinal injury, immunohistological staining studies for FAS ligand in the spinal cord tissue was done. The spinal sections of sham-operated mice failed to exhibit FAS ligand staining (Figure 8B), whereas significant positive staining was seen in vehicle-treated group mainly located in white and gray portion of the spinal cord and the inflammation affected cells (Figures 4 and 8A). However, after receiving

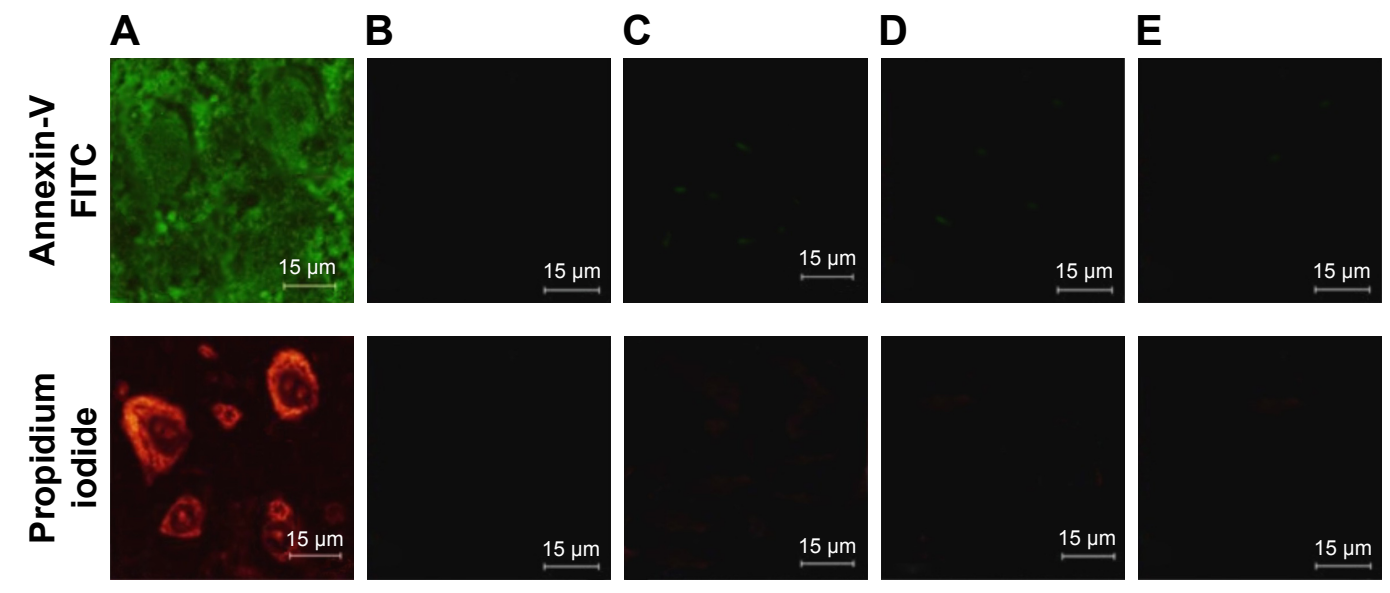

Figure 6 Apoptosis studies after $24 \mathrm{~h}$ of spinal injury. Control group mice showed positive staining for Annexin-V FITC indicating the cells undergoing apoptosis.

Notes: Late-stage apoptosis was also shown by positive staining for PI in control group mice (A). The sham-group mice did not stain positive for Annexin-V and PI (B). The mice treated with pseudohypericin (C), zafirlukast (D) and their combination (E) demonstrated significant downfall in Annexin-V and PI-positive cells, the results were highly significant with their combination.

Abbreviation: $\mathrm{PI}$, propidium iodide. 

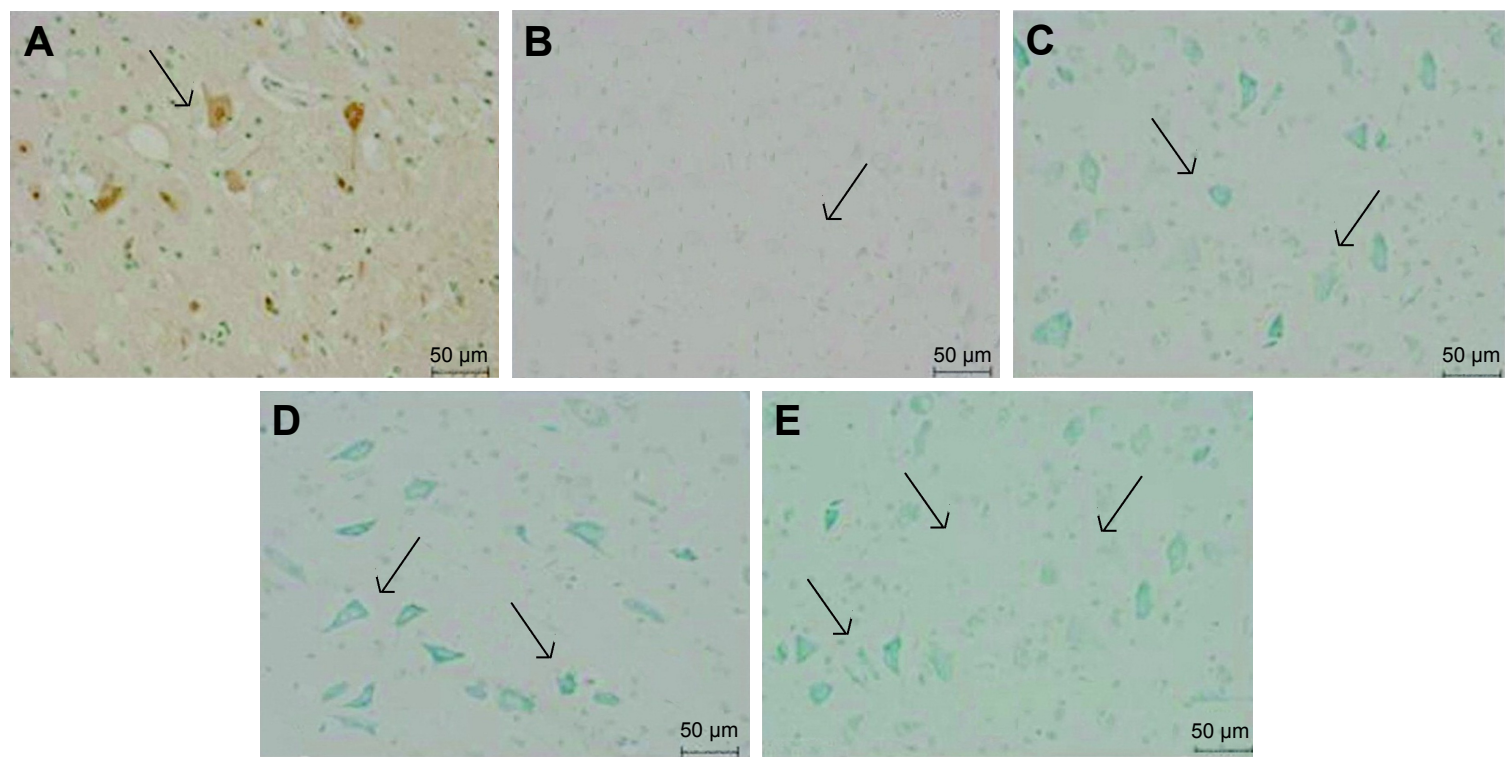

Figure 7 TUNEL assay of spinal cord tissue of mice subjected to spinal injury followed by treatment of pseudohypericin, zafirlukast and their combination.

Notes: The tissue harvested after $24 \mathrm{~h}$ of injury and received treatment of vehicle only showed appearance of brown color cells suggesting apoptosis (A). In contrast the tissues of mice treated with pseudohypericin (C), zafirlukast (D) and their combination (E) demonstrated reduction in number of apoptotic cells, no apoptotic fragments were detected in sham-operated vehicle-treated mice spinal tissues (B). TUNEL-terminal deoxynucleotidyltransferase-mediated UTP end labeling assay. The arrows indicate the TUNEL positive cells.

Abbreviation: TUNEL, terminal deoxynucleotidyltransferase-mediated UTP end labeling.

treatment of PHP or ZFL alone, reduction in the extent of positive staining for FAS ligand was observed in the spinal tissue (Figure 8C-E). The tissue sections of PHP-ZFLtreated mice showed highly significant reduction in FAS ligand staining compared to control group of mice.

\section{Effects of PHP and ZFL on levels of Bax and $\mathrm{Bcl}-2$}

Immunohistological staining and Western blot studies were done to evaluate the effect of PHP and ZFL on Bcl-2 and Bax. The spinal tissue sections of mice that had undergone sham
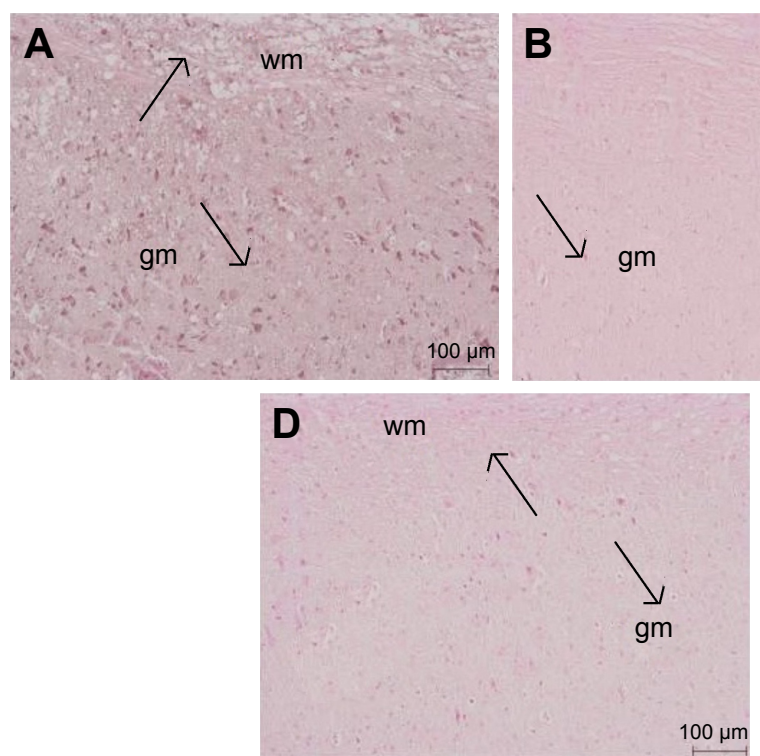
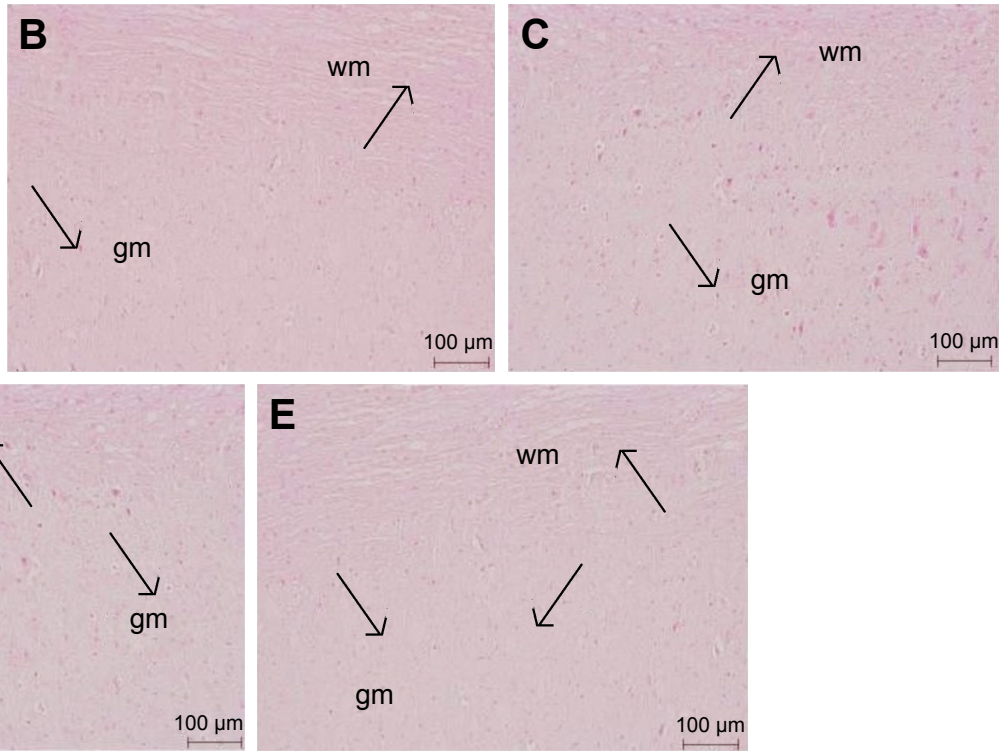

Figure 8 Results of immunohistological staining for FAS-L.

Notes: The spinal tissues sections obtained after $24 \mathrm{~h}$ of spinal injury showed positive staining for FAS-L (A). The spinal tissue sections of mice after receiving treatment of pseudohypericin (C) and zafirlukast (D) showed decrease in number of cells positive for FAS-L. The positive stained FAS-L cells reduced more significantly in spinal tissues of mice receiving combined treatment of pseudohypericin and zafirlukast (E). The sham-operated mice tissues showed no staining for FAS-L (B). The arrows indicate the staining for FAS-L in spinal tissues.

Abbreviations: FAS-L, FAS ligand; wm, white matter; gm, gray matter. 

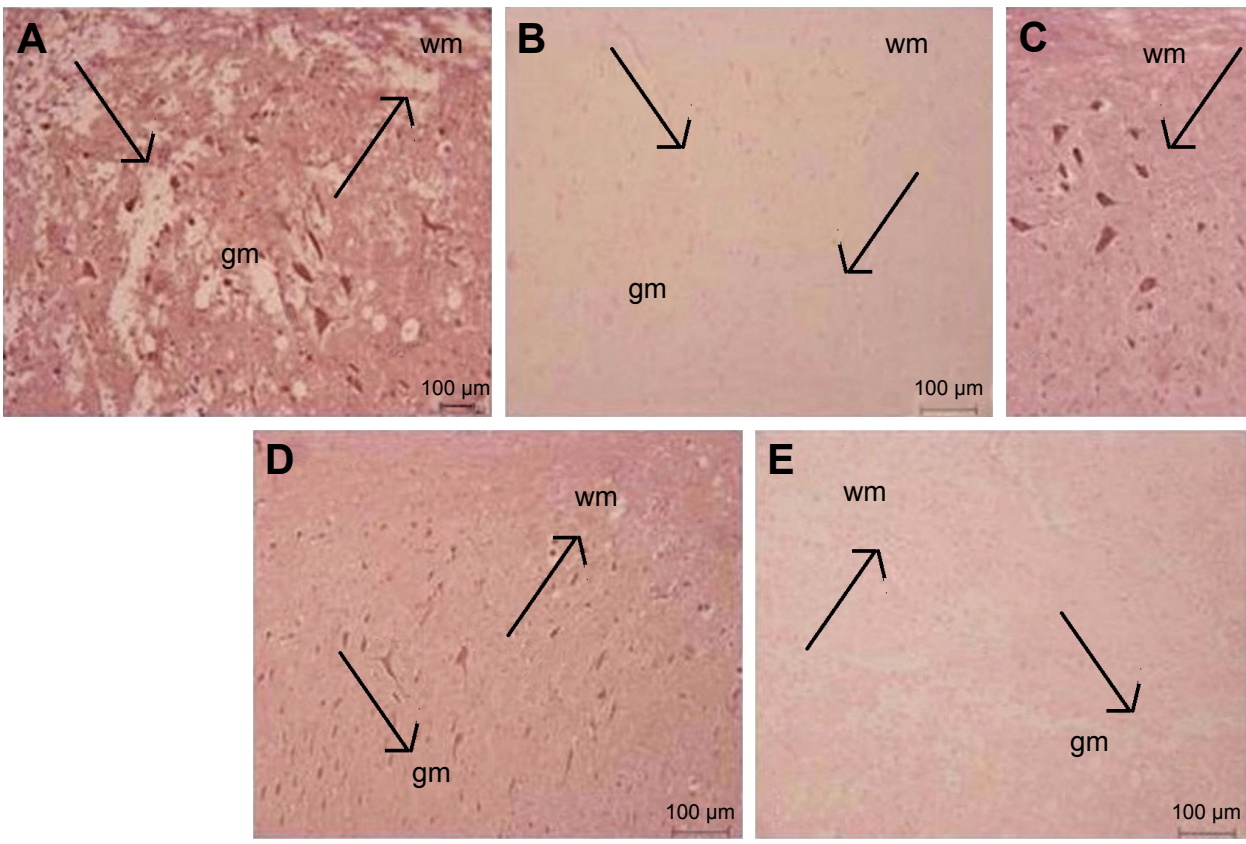

Figure 9 Effect of pseudohypericin and zafirlukast treatment on Bax staining in spinal tissues of mice.

Notes: The degree of positive staining was higher in vehicle-treated control mice tissues (A). (B) Sham-group did not exhibit positive staining. The extent of Bax staining decreased in pseudohypericin (C)- and zafirlukast (D)-treated mice tissues compared to control. The results were even better and degree of positive staining for Bax decreased further in tissues of mice treated with combination of pseudohypericin and zafirlukast $(\mathbf{E})$. The arrows indicate the Bax staining in spinal tissues.

Abbreviations: wm, white matter; gm, gray matter.

surgery showed a negative immunohistochemical staining for Bax, whereas positive staining for Bax was seen in the vehicle-treated control group (Figures 4 and $9 \mathrm{~A}$ and $\mathrm{B}$ ). The spinal tissue from PHP- or ZFL-treated mice exhibited reduced Bax staining (Figures 4 and $9 \mathrm{C}$ and $\mathrm{D}$ ), whereas significant reduction $(P<0.01)$ was seen in tissue sections of PHP-ZFL-treated mice (Figures 4 and 9E). The expression levels of Bax were confirmed further in tissue homogenates by Western blot technique post $24 \mathrm{~h}$ of spinal injury. Expression of Bax levels increased significantly $(P<0.01)$ in the vehicle-treated control group compared to sham-operated mice (Figure 10). However, the treatment of PHP or ZFL resulted in decreased expression of Bax, a significant reduction in levels was observed in tissue homogenates of mice receiving combined treatment of PHP and ZFL.

Tissue sections of sham-operated mice showed positive staining for Bcl-2 and low staining in vehicle-treated control group mice (Figures 4 and 11A). The sham group showed no staining (Figure 11B). The extent of positive staining decreased in mice receiving treatment of PHP (Figures 4 and 11C) or ZFL (Figures 4 and 11D). Significant results were seen in tissue sections of mice receiving treatment of PHP-ZFL in combination (Figures 4 and 11E). The results of Western blot were parallel to immunohistology, the expression of Bcl-2 was high in spinal homogenates of sham-operated mice (Figure 11), whereas the expression levels were significantly low in vehicle-treated mice post $24 \mathrm{~h}$ of spinal injury. The PHP and ZFL treatments elevated the Bcl-2 levels, with significant results when treated in combination (Figure 12).

\section{Effects of PHP and ZFL on expression of COX-2 and activation of MAPK}

Western blot analysis was done to evaluate the expression of COX-2 and extent of ERK-1/2 phosphorylation from the spinal tissue homogenates. The results showed a basal level expression of COX-2 in tissue homogenates of shamoperated mice (Figure 13), whereas the levels were highly elevated in vehicle-treated mice. The blots showed reduced expression of COX-2 in tissue homogenates of PHP- and ZFL-treated mice, significant $(P<0.01)$ downfall in COX-2 expression was found in mice treated with PHP and ZFL in combination compared to vehicle-treated group.

To find whether the increased levels of COX-2 corresponds activation of signal transduction pathways which is responsible for regulating the expression of COX-2, we evaluated MAPK activation specifically the ERK-1/2 phosphorylation after $24 \mathrm{~h}$ of spinal injury. The results of our study (Figure 14) suggested increased levels of pERK-1/2 

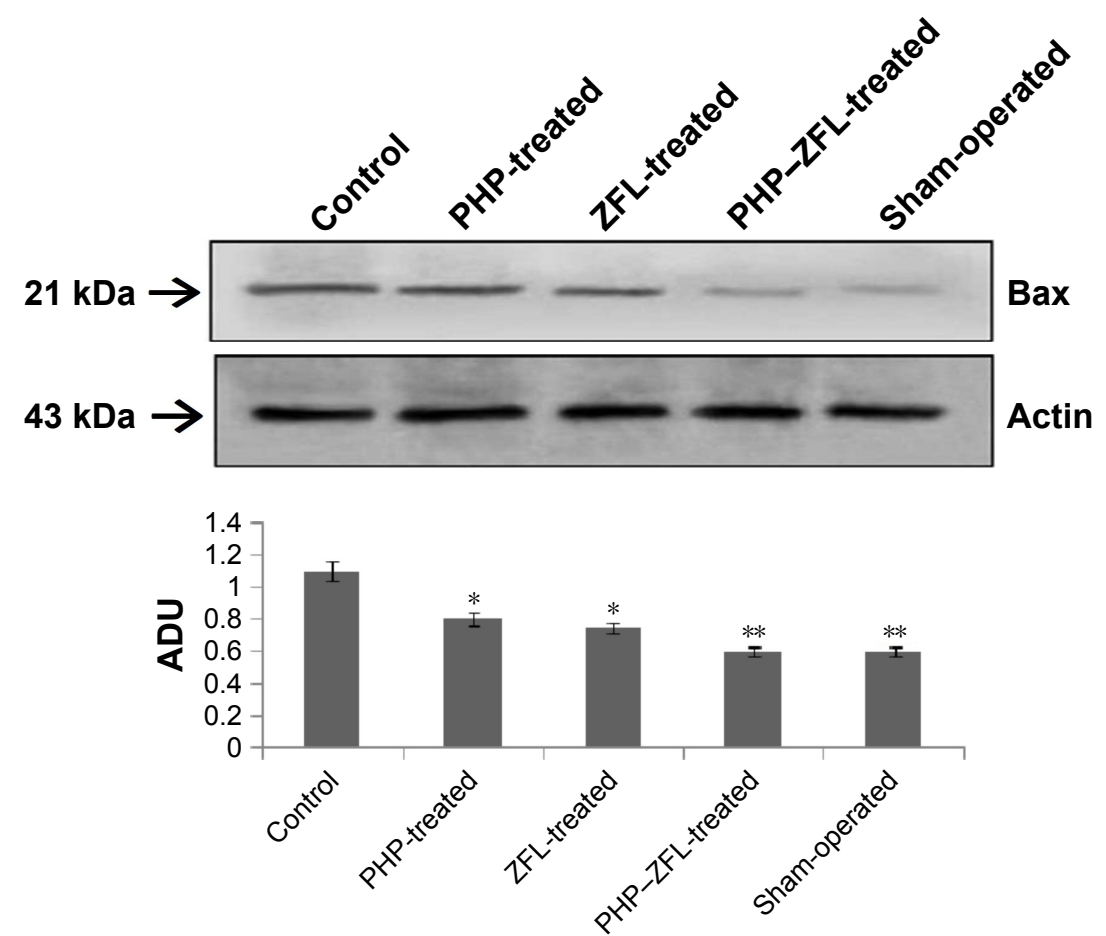

Figure 10 Western blot and densitometry analysis were done on the tissue homogenates of spinal tissue collected $24 \mathrm{~h}$ after inducing injury.

Notes: Expression of Bax levels was more prominent in tissues of vehicle-treated mice. The expression levels decreased significantly $(* P<0.05)$ in PHP- and ZFL-treated mice, whereas the levels reduced more significantly $\left({ }^{*} P<0.0 \mathrm{I},{ }^{*} * \mathrm{P}<0.00 \mathrm{I}\right)$ in mice treated with combination. All the data were normalized against actin levels as loading control.

Abbreviations: PHP, pseudohypericin; ZFL, zafirlukast; ADU, arbitrary density units.

in the spinal tissue of mice treated with vehicle, whereas the dosing of PHP or ZFL decreased it, significant results were observed with tissues of mice treated with PHP-ZFL in combination (Figure 14).

\section{Effects of PHP and ZFL on output of $\mathrm{PGE}_{2}$ and $\mathrm{LTB}_{4}$}

The spinal tissues of vehicle-treated mice were found to have increased levels of $\mathrm{PGE}_{2}$ and $\mathrm{LTB}_{4} 24 \mathrm{~h}$ after injury. Signs of
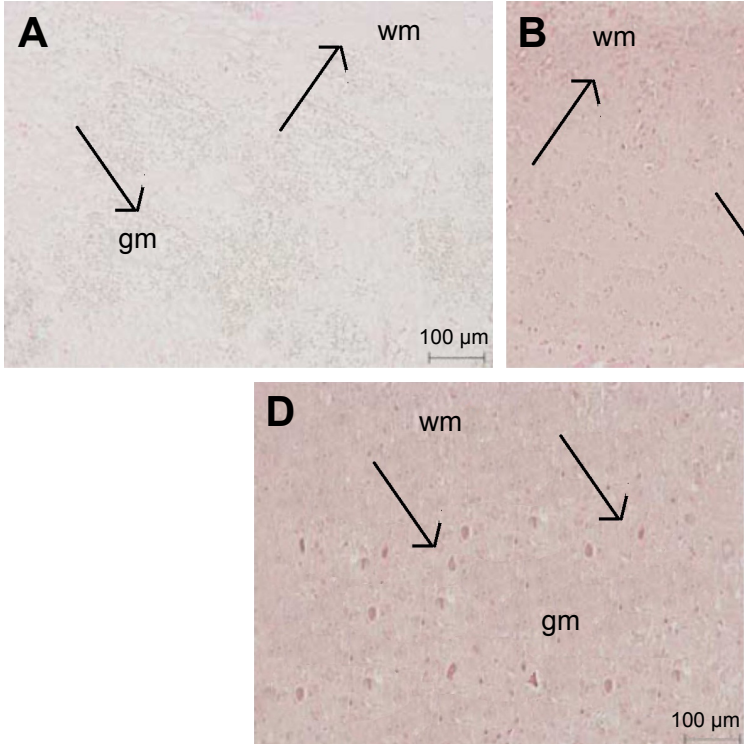
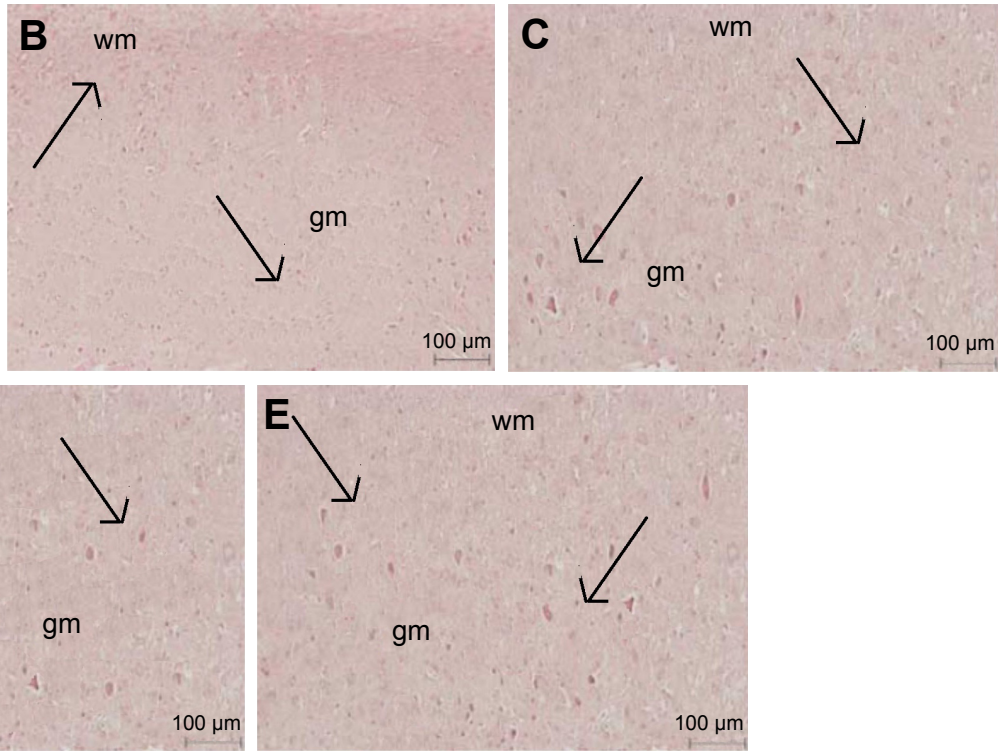

Figure I I Evaluation of spinal tissues for Bcl-2 levels, after $24 \mathrm{~h}$ of injury.

Note: The control vehicle-treated $(\mathbf{A})$ mice showed reduction in positive staining for $\mathrm{Bcl}-2$, whereas the positive staining for Bcl-2 increased in tissues of sham-group mice (B), treated with pseudohypericin (C), zafirlukast (D) and their combination (E). The arrows show positive staining for Bcl-2.

Abbreviations: wm, white matter; gm, gray matter. 

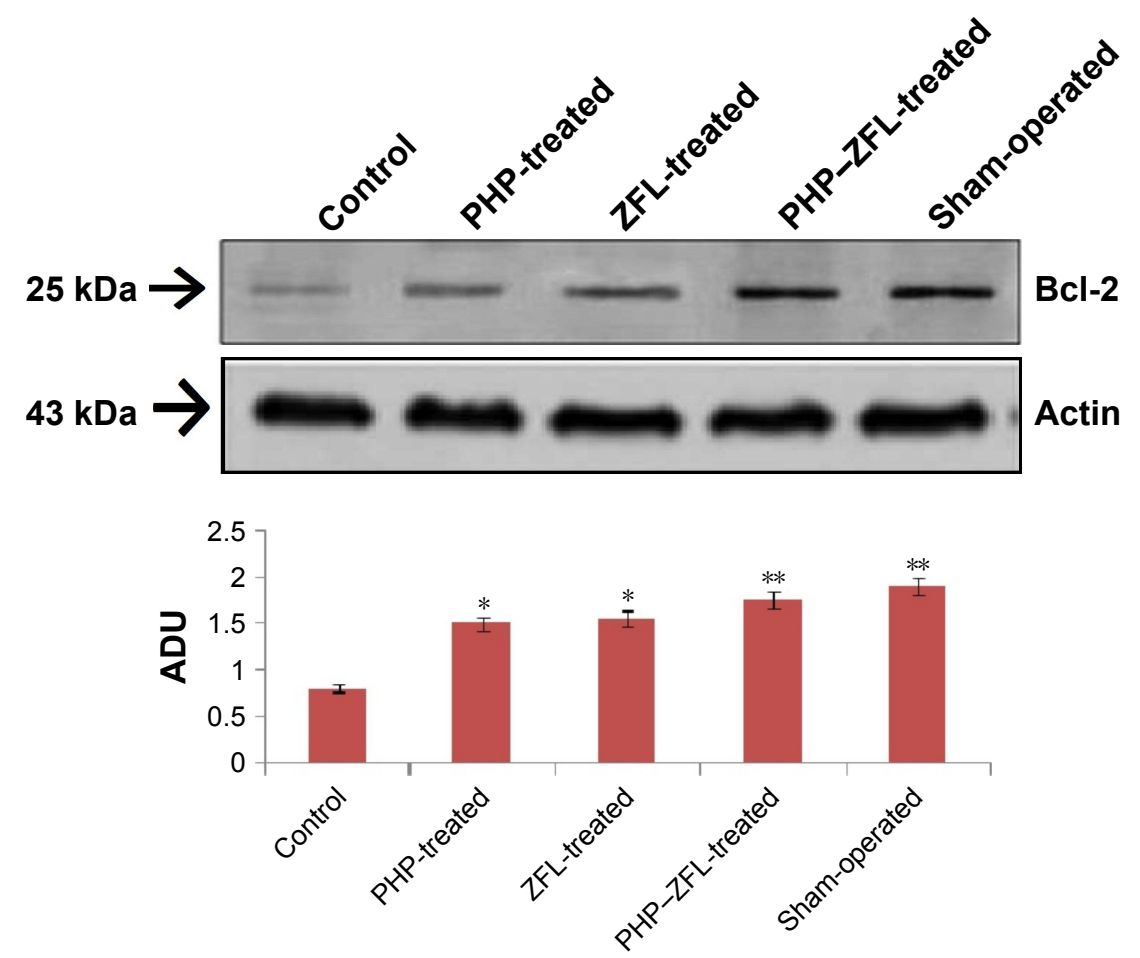

Figure 12 Western blot and densitometry analysis were done on the tissue homogenates of spinal tissue collected $24 \mathrm{~h}$ after inducing injury.

Notes: Expression of Bcl-2 levels decreased in tissues of vehicle-treated mice. The expression levels increased significantly ( $* P<0.05)$ in PHP- and ZFL-treated mice, whereas the levels increased more significantly $(* * P<0.00 \mathrm{I})$ in mice treated with combination compared to control group. All the data were normalized against actin levels as loading control.

Abbreviations: PHP, pseudohypericin; ZFL, zafirlukast; ADU, arbitrary density units.
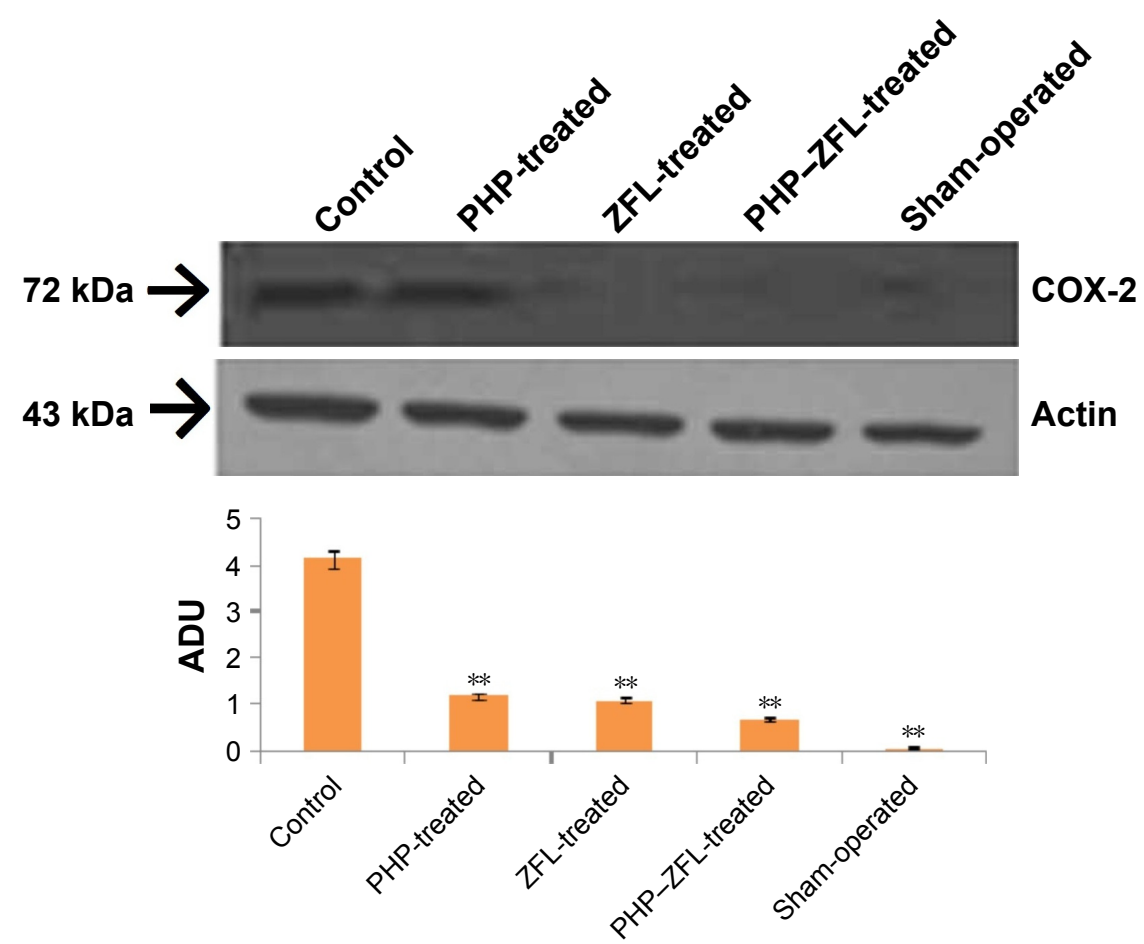

Figure 13 Western blot and densitometry analysis were done on the tissue homogenates of spinal tissue collected $24 \mathrm{~h}$ after inducing injury.

Notes: The spinal injury resulted in increased expression of COX-2 in tissues of vehicle-treated mice. The expression levels decreased more significantly ( $* * P<0.0 \mathrm{I})$ in $\mathrm{PHP}$, ZFL and their combination compared to control group. All the data were normalized against actin levels as loading control.

Abbreviations: COX-2, cyclooxygenase-2; PHP, pseudohypericin; ZFL, zafirlukast; ADU, arbitrary density units. 

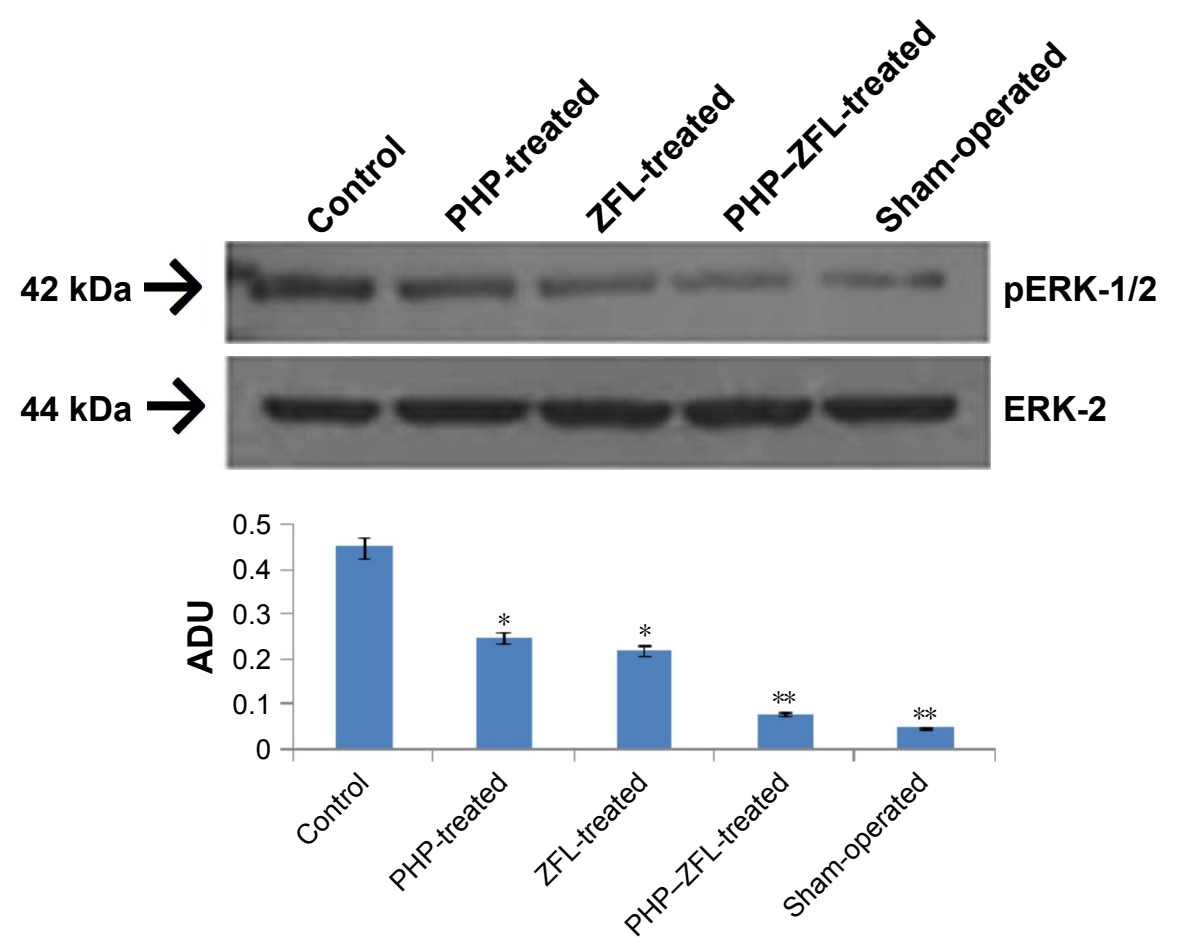

Figure 14 Western blot and densitometry analysis were done on the tissue homogenates of spinal tissue collected $24 \mathrm{~h}$ after inducing injury.

Notes: Extent of ERK-I/2 phosphorylation increased in tissues of vehicle-treated mice. The expression levels decreased significantly $\left({ }^{*} P<0.05\right)$ in PHP- and ZFL-treated mice, whereas the decrease in levels was more significant $(* * P<0.001)$ in mice treated with combination compared to control group. All the data were normalized against ERK-2 levels as loading control.

Abbreviations: ERK-I/2, extracellular signal-regulated kinase-I/2; pERK-I/2, phosphorylation of ERK-I/2; PHP, pseudohypericin; ZFL, zafirlukast; ADU, arbitrary density units.

attenuation were seen in mice treated with PHP or ZFL, marked by decreased levels of $\mathrm{PGE}_{2}$ and $\mathrm{LTB}_{4}$, whereas a significant reduction in levels was observed in mice receiving combined treatment of PHP and ZFL (Figure 15A and B).

\section{Discussion}

The pharmacotherapy for treating SCI is based upon the existence of three stages: the acute, the subacute and the chronic stages. The acute stage is accompanied by an inflammatory response, oxidative stress and excitotoxicity. The treatment approach is to reduce them. ${ }^{25}$ The subacute stage is associated with neuronal damage. Initiation of therapies for increasing cell survival and reducing neuronal damage may help in repair of the damaged tissue. ${ }^{26}$ However, the treatment of chronic stage SCI involves the use of mesenchymal stem cell transplantation along with agents for increasing cell survival. ${ }^{27}$ In spite of this, a limited number of pharmacotherapy options are available for correcting SCI. Continuous knowledge for the etiopathogenesis of SCI suggesting various molecular mechanisms will lead to the discovery of new pharmacotherapies for treating SCI.

PHP is an active compound of the plant $H$. perforatum (St John's wort). It is a structural derivative of naphthodianthrones, the class of compounds which have been confirmed
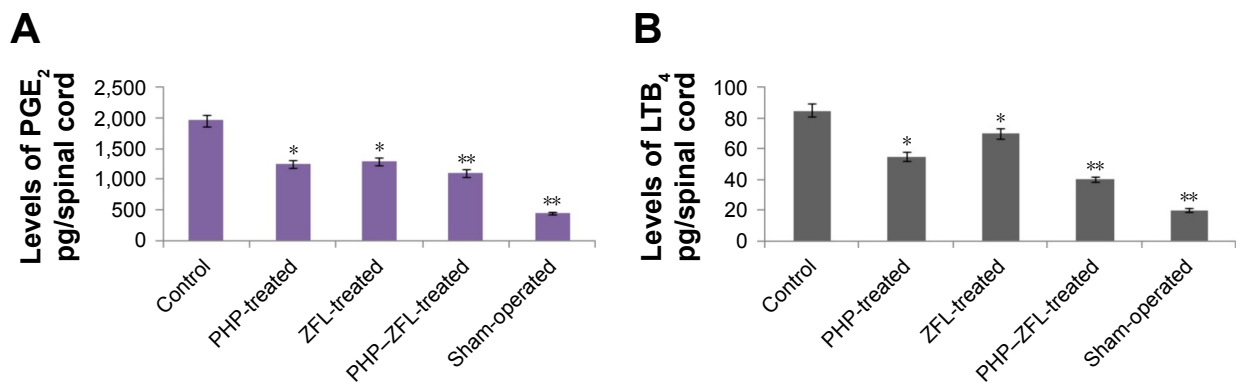

Figure 15 Effect of PHP and ZFL on levels of $\mathrm{PGE}_{2}(\mathbf{A})$ and $\mathrm{LTB}_{4}(\mathbf{B})$.

Notes: The levels were measured in spinal tissues obtained $24 \mathrm{~h}$ after injury. The tissues levels of $\mathrm{PGE}_{2}$ and $\mathrm{LTB}_{4}$ were elevated on vehicle-treated group. $\mathrm{A}$ significant decrease in levels of $\mathrm{PGE}_{2}$ and $\mathrm{LTB}_{4}$ was observed in PHP- and ZFL-treated mice $(* P<0.05)$ compared to control. The decrease in levels was highly significant $(* * P<00 \mathrm{I})$ in group treated with combination of PHP and ZFL.

Abbreviations: PHP, pseudohypericin; ZFL, zafirlukast; $P G E_{2}$, prostaglandin $E_{2}$; LTB $_{4}$, leukotriene $B_{4}$. 
for antilipoxygenase activity ${ }^{19}$, ie, a 5-LO inhibitor. In the present work, we hypothesized that PHP being a derivative of naphthodianthrone can result in 5-LO inhibitory activity. ZFL is a Cys-LT1 antagonist used in treating SCI. No reports indicating evaluation of 5-LO inhibitory activity of PHP have been reported. In this report, we evaluated the effect of PHP and ZFL alone in SCI-induced mice model. We also evaluated the effect of PHP in combination with ZFL.

PHP and ZFL, when administered alone, showed attenuating effect in mice induced to SCI. The effect increased when PHP was combined with ZFL. The core findings of the present work are that treatment with PHP or ZFL attenuated motor activity, tissue injury, reduced apoptosis-mediated cell death, decreased rate of neutrophils' infiltration, activation of ERK-1/2, TNF- $\alpha$ and levels of COX-2 in SCI-induced mice. The effects were significantly improved when both the agents were combined. The findings of the study conclude our hypothesis for PHP, proving its 5-LO inhibitory activity and its usefulness in treating SCI.

The outcomes of the study confirm the involvement of 5-LO and Cys-LTs in spinal injury. A study suggested, an overactive 5-LO pathway can cause neurodegeneration via increasing the migration of neutrophils, also $\mathrm{LTB}_{4}$ and Cys-LTs are one of the strongest factors responsible for facilitation of cells to the site of inflammation. ${ }^{28}$ Here in this study, SCI-induced mice on treatment with PHP and ZFL demonstrated a significant decrease in infiltration of leukocytes, tissue damage and production of LT, along with improvement in motor function.

It has been evidenced that LTs along with TNF- $\alpha$ and COX-2 play an important role in causing inflammation and neurodegeneration. ${ }^{29,30} \mathrm{~A}$ study have concluded clear role of COX-2 along with TNF- $\alpha$ in the pathogenesis of SCI. ${ }^{14}$ In present study, outcomes of immunohistochemistry showed a significant rise in levels of TNF- $\alpha$ in spinal cord-injured mice treated with vehicle compared to the sham-operated mice, the outcomes were in agreement to a previous report. ${ }^{14}$

Lipopolysaccharide/interferon-g is responsible for increased expression of COX-2 via signal transduction by MAPK family proteins (ERK-1 and ERK-2). ${ }^{30}$ The activation of MAPK specifically is correlated with phosphorylation of both ERK-1 and ERK-2 via activation of receptor Cys-LT1. The results of our study were in association to these studies, the SCI-induced mice treated with PHP, ZFL or combination of PHP-ZFL demonstrated decreased levels of COX-2, PGE-2 and pERK-1/2 compared to vehicle-treated mice.

A study have concluded the role of LTs in the proliferation of neuronal cells. ${ }^{31}$ Apoptosis is found to be the major contributing factor in secondary damage after SCI. ${ }^{32}$ The results of Annexin-V, TUNEL assay, and Fas ligand staining showed that PHP and ZFL resulted in inhibition of 5-LO and also reduced cell apoptosis in tissues of spinal injured mice. The results were in association with previous studies done in 5-LO knockout mice subjected to SCI, ${ }^{33}$ which suggest that the effect may be due to inhibition of infiltration of neutrophils. In earlier reports, the decrease in infiltration of neutrophils in the absence of 5-LO may have attenuated the burden of reactive oxygen species. ${ }^{34,35}$

Transcriptional factor such as Bax is a proapoptotic protein which has been evidenced to play a critical role in causing cell death and CNS injury. ${ }^{36,37} \mathrm{Bcl}-2$ is the most expressed antiapoptotic protein in CNS, the expression of which decreases in case of injury. ${ }^{38}$ Based on the evidence related to transcriptional changes in SCI, Western blot and immunohistochemical staining studies were done. We observed that PHP, ZFL and their combination ameliorated the transcriptional changes related to apoptosis mediated by spinal injury.

\section{Conclusion}

Our study established PHP as a 5-LO antagonist and its postulated neuroprotective role along with ZFL. The combination of PHP along with ZFL resulted in a potential ameliorating action in SCI mice. The treatment of PHP and ZFL corrected motor function, decreased tissue injury, infiltration of neutrophils at the site, apoptosis, expression of pERK-1/2 and levels of TNF- $\alpha$ and COX-2. Altogether the study proves PHP along with $\mathrm{ZFL}$ as potential combination in treating spinal injury by reducing inflammatory effects in SCI-induced mice and confirms involvement of 5-LO antagonist and Cys-LTs for correcting spinal injury.

\section{Acknowledgments}

We express thanks to the management and staff of Huai'an First People's Hospital, Nanjing Medical University, Huai'an, Jiangsu, China, for providing necessary facilities. Hereby we declare that our institutes are aware of the work and declare consent for publication of the manuscript. The work was self-financed and hence we declare no acknowledgments for any funding agency.

\section{Disclosure}

The authors report no conflicts of interest in this work.

\section{References}

1. Beattie MS. Inflammation and apoptosis: linked therapeutic targets in spinal cord injury. Trends Mol Med. 2004;10(12):580-583.

2. Gris D, Marsh DR, Oatway MA, et al. Transient blockade of the CD11d/ CD18 integrin reduces secondary damage after spinal cord injury, improving sensory, autonomic, and motor function. J Neurosci. 2004 24(16):4043-4051 
3. Carlson GD, Gorden C. Current developments in spinal cord injury research. Spine J. 2002;2(2):116-128.

4. Anderson AJ. Mechanisms and pathways of inflammatory responses in CNS trauma: spinal cord injury. J Spinal Cord Med. 2002;25(2):70-79.

5. Jung SB, Song CH, Yang CS, et al. Role of the phosphatidylinositol 3-kinase and mitogen-activated protein kinase pathways in the secretion of tumour necrosis factor-alpha and interleukin- 10 by the PPD antigen of Mycobacterium tuberculosis. J Clin Immunol. 2005;25(5):482-490.

6. Taoka Y, Okajima K, Uchiba M, et al. Role of neutrophils in spinal cord injury in the rat. Neuroscience. 1997;79(4):1177-1182.

7. Carlson SL, Parrish ME, Springer JE, Doty K, Dossett L. Acute inflammatory response in spinal cord following impact injury. Exp Neurol. 1998;151(1):77-88.

8. McTigue DM, Tani M, Krivacic K, et al. Selective chemokine mRNA accumulation in the rat spinal cord after contusion injury. $J$ Neurosci Res. 1998;53(3):368-376.

9. Erşahin M, Çevik Ö, Akakın D, et al. Montelukast inhibits caspase-3 activity and ameliorates oxidative damage in the spinal cord and urinary bladder of rats with spinal cord injury. Prostaglandins Other Lipid Mediat. 2012;99(3-4):131-139.

10. Dietrich WD, Chatzipanteli K, Vitarbo E, Wada K, Kinoshita K. The role of inflammatory processes in the pathophysiology and treatment of brain and spinal cord trauma. Acta Neurochir Suppl. 2004;89:69-74.

11. Profyris C, Cheema SS, Zang D, Azari MF, Boyle K, Petratos S. Degenerative and regenerative mechanisms governing spinal cord injury. Neurobiol Dis. 2004;15(3):415-436.

12. Suttorp N, Seeger W, Zucker-Reimann J, Roka L, Bhakdi S. Mechanism of leukotriene generation in polymorphonuclear leukocytes by staphylococcal alpha-toxin. Infect Immun. 1987;55(1):104-110.

13. Mitsuhashi T, Ikata T, Morimoto K, Tonai T, Katoh S. Increased production of eicosanoids, TXA2, PGI2 and LTC4 in experimental spinal cord injuries. Paraplegia. 1994;32(8):524-530.

14. Adachi K, Yimin Y, Satake K, et al. Localization of cyclooxygenase-2 induced following traumatic spinal cord injury. Neurosci Res. 2005; 51(1):73-80.

15. Nishisho T, Tonai T, Tamura Y, Ikata T. Experimental and clinical studies of eicosanoids in cerebrospinal fluid after spinal cord injury. Neurosurgery. 1996;39(5):950-956.

16. Cameron DW, Raverty WD. Pseudohypericin and other phenanthroperylene quinones. Aust J Chem. 1976;29:1523-1533.

17. Apaydin S, Zeybek U, Ince I, et al. Hypericum triquetrifolium Turra extract exhibits antinociceptive activity in the mouse. J Ethnopharmacol. 1999;67(3):307-312.

18. Kimberly DPH, Matthew LH, Jeffrey DN, et al. Pseudohypericin is necessary for the light-activated inhibition of prostaglandin $\mathrm{E}_{2}$ pathways by a 4 component system mimicking an Hypericum perforatum fraction. Phytochemistry. 2008;69(12):2354-2362.

19. Obložinský M, Bezáková L, Holková I, Vanko M, Kartnig T, Pšenák M. Antilipoxygenase activity of compounds from Hypericum perforatum. Biologia. 2006;61(3):331-332.

20. Al-Amran FG, Hadi NR, Hashim AM. Cysteinyl leukotriene receptor antagonist montelukast ameliorates acute lung injury following haemorrhagic shock in rats. Eur J Cardiothorac Surg. 2013;43(2):421-427.

21. Meruelo D, Lavie G, Lavie D. Therapeutic agents with dramatic antiretroviral activity and little toxicity at effective doses: aromatic polycyclic diones hypericin and pseudohypericin. Proc Natl Acad Sci U S A. 1988; 85(14):5230-5234.

Drug Design, Development and Therapy

\section{Publish your work in this journal}

Drug Design, Development and Therapy is an international, peerreviewed open-access journal that spans the spectrum of drug design and development through to clinical applications. Clinical outcomes, patient safety, and programs for the development and effective, safe, and sustained use of medicines are the features of the journal, which

Submit your manuscript here: http://www.dovepress.com/drug-design-development-and-therapy-journa
22. Basso DM, Beattie MS, Bresnahan JC. A sensitive and reliable locomotor rating scale for open field testing in rats. J Neurotrauma. 1995; 12(1): $1-21$.

23. Joshi M, Fehlings MG. Development and characterization of a novel, graded model of clip compressive spinal cord injury in the mouse: part 1. Clipdesign, behavioral outcomes and histopathology. J Neurotrauma. 2002;19(2):175-190.

24. Mullane KM, Kraemer R, Smith B. Myeloperoxidase activity as a quantitative assessment of neutrophil infiltration into ischemic myocardium. J Pharmacol Methods. 1985;14(3):157-167.

25. Bracken MB, Shepard MJ, Collins WF, et al. A randomized, controlled trial of methylprednisolone or naloxone in the treatment of acute spinal cord injury. N Engl J Med. 1990;322(20):1405-1411.

26. Geisler FH, Dorsey FC, Coleman WP. GM-1 ganglioside in human spinal cord injury. J Neurotrauma. 1992;9(suppl 2):S517-S530.

27. Diener PS, Bregman BS. Fetal spinal cord transplants support growth of supraspinal and segmental projections after cervical spinal cord hemisection in the neonatal rat. J Neurosci. 1998;18(2):779-793.

28. Virchow JC, Faehndrich S, Nassenstein C, Bock S, Matthys H, Luttmann W. Effect of a specific cysteinyl leukotrienereceptor 1 -antagonist (montelukast) on the transmigration of eosinophils across human umbilical vein endothelial cells. Clin Exp Allergy. 2001;31(6): 836-844.

29. Ichiyama T, Kajimoto M, Hasegawa M, Hashimoto K, Matsubara T, Furukawa S. Cysteinyl leukotrienes enhance tumour necrosis factoralpha-induced matrix metalloproteinase- 9 in human monocytes/ macrophages. Clin Exp Allergy. 2007;37(4):608-614.

30. Rossi A, Acquaviva AM, Iuliano F, Di Paola R, Cuzzocrea S, Autebin L. Up-regulation of prostaglandin biosynthesis by leukotriene $\mathrm{C} 4$ in elicited mice peritoneal macrophages activated with lipopolysaccharide/ interferon-g. J Leuk Biol. 2005;78:985-991.

31. Wada K, Arita M, Nakajima A, et al. Leukotriene B4 and lipoxin A4 are regulatory signals for neural stem cell proliferation and differentiation. FASEB J. 2006;20(11):1785-1792.

32. Beattie MS, Hermann GE, Rogers RC, Bresnahan JC. Cell death in models of spinal cord injury. Prog Brain Res. 2002;137:37-47.

33. Genovese T, Mazzon E, Rossi A, et al. Involvement of 5-lipoxygenase in spinal cord injury. J Neuroimmunol. 2005;166(1-2):55-64.

34. Cuzzocrea S, Rossi A, Mazzon E, et al. 5-lipoxygenase modulate the development of colitis in mice through the regulation of adhesion molecules expression. Lab Invest. 2005;85(6):808-822.

35. Xu W, Chi L, Xu R, et al. Increased production of reactive oxygen species contributes to motor neuron death in a compression mouse model of spinal cord injury. Spinal Cord. 2005;43(4):204-213.

36. Chittenden T, Harrington EA, O'Connor R, et al. Induction of apoptosis by the Bcl-2 homologue Bak. Nature. 1995;374(6524):733-736.

37. Bar-Peled O, Knudson M, Korsmeyer SJ, Rothstein JD. Motor neuron degeneration is attenuated in Bax-deficient neurons in vitro. $J$ Neurosci Res. 1999;55(5):542-556.

38. Nesic-Taylor O, Cittelly D, Ye Z, et al. Exogenous Bcl-xL fusion protein spares neurons after spinal cord injury. $J$ Neurosci Res. 2005; 79(5):628-637.

has also been accepted for indexing on PubMed Central. The manuscript management system is completely online and includes a very quick and fair peer-review system, which is all easy to use. Visit http://www.dovepress.com/testimonials.php to read real quotes from published authors. 